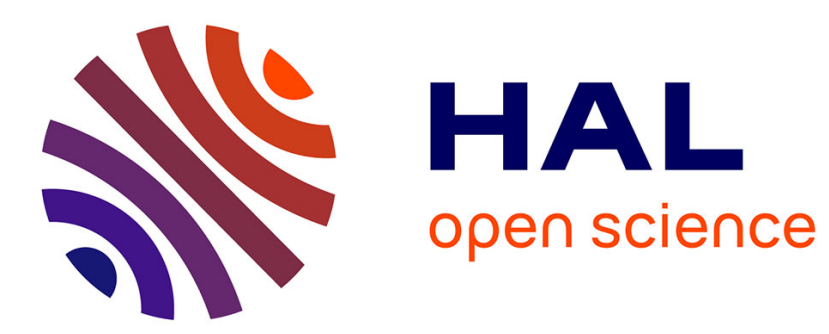

\title{
Inflation target and (a)symmetries in the oil price pass-through to inflation
}

Antonia Lòpez-Villavicencio, Marc Pourroy

\section{To cite this version:}

Antonia Lòpez-Villavicencio, Marc Pourroy. Inflation target and (a)symmetries in the oil price passthrough to inflation. Energy Economics, 2019, 80, pp.860-875. 10.1016/j.eneco.2019.01.025 . hal02082415

\section{HAL Id: hal-02082415 https://hal.science/hal-02082415}

Submitted on 28 Mar 2019

HAL is a multi-disciplinary open access archive for the deposit and dissemination of scientific research documents, whether they are published or not. The documents may come from teaching and research institutions in France or abroad, or from public or private research centers.
L'archive ouverte pluridisciplinaire HAL, est destinée au dépôt et à la diffusion de documents scientifiques de niveau recherche, publiés ou non, émanant des établissements d'enseignement et de recherche français ou étrangers, des laboratoires publics ou privés. 


\title{
Inflation target and (a)symmetries in the oil price pass-through to inflation
}

\author{
ANTONIA LÓPEZ-VILLAVICENCIO* \\ GATE-CNRS, UniversityLyon 2, France. (e-mail: lopez@gate.cnrs.fr). \\ MARC POURROY \\ University of Poitiers. France. (e-mail: marc.pourroy@univ-poitiers.fr).
}

\begin{abstract}
In this paper we employ state-space models to estimate the pass-through of oil price changes to consumer prices for a large sample of countries from 1970 to 2017. By controlling for self-selection bias and endogeneity and allowing for different responses to positive and negative price changes, we asses the differences between explicit inflation targeting (IT) countries and a control group. Surprisingly perhaps, our results suggest that the pass-through is higher for IT countries. Our main contribution is to show that these is mainly due to IT countries having a significant higher pass-through than non-IT countries when the oil price decreases: a $10 \%$ drop in oil price leads about a $0.11 \%$ drop in inflation in ITers (of which 4pp are explained by the monetary regime). Importantly, we show that adopting IT reduces the asymmetry of the pass-through. We run several robustness checks and conclude that falling oil prices are more welcomed by the central banks with an IT framework, in particular during deflationary episodes or when inflation is above the target.
\end{abstract}

JEL Classification: E31; E42; Q43.

Keywords: oil price, pass-through; inflation targeting; state-space model; propensity score matching.

\footnotetext{
* Corresponding author: Antonia Lopez-Villavicencio, GATE-CNRS andUniversity Lumière Lyon 2. 93, chemin des Mouilles - B.P.167 69131 - ECULLY cedex, France. Phone: + 33 (0) 4728660 87. Email: lopez@gate.cnrs.fr. The authors would like to thank Grégory Levieuge and his co-authors for providing us with their data.We are especially grateful to anonymous referees for their thoughtful comments.
} 
Highlights:

- We estimate the impact of inflation targeting on the oil price pass-through to domestic inflation using a large sample of countries from 1970 to 2017

- When oil price increases but inflation remains low, the pass-through is lower in IT countries, consistent with conservative preferences

- When oil price increases and inflation is high, we do not find any difference between IT and non-IT countries

- When oil price decreases, the pass-through is significantly larger in IT countries

- This is observed particularly during deflationary events or when inflation is above target

- The asymmetric oil price pass-through to inflation may partly be explained by monetary policy reactions 


\section{Introduction}

Understanding the link between oil prices and consumer prices is crucial for monetary authorities attempting to keep inflation under control. It is no wonder, thus, that oil pass-through (OPT from now on) has attracted considerable interest in recent years. Several papers have improved our understanding on the subject by confirming that, historically, oil price swings and inflation have been positively correlated, even though this relationship has varied widely across countries. In addition, it is suggested that: i) the pass-through of oil price changes to prices has weakened since the mid-eighties and ii) the effects of oil prices on inflation depends on the direction of the changes in prices, the magnitude of the pass-through being greater when oil prices rise than when they fall.

Indeed, it is proposed that improved monetary policy may account for a part of the decline in the oil pass-through (see Otker, et al. (2009) or Choi, et al. (2018)). In particular, the better conduct of monetary policy has increase credibility: by better anchoring inflation expectations, an unexpected increase in inflation -due to events such as oil price shocks- does not lead to a change in inflation expectations. For instance, Hooker (2002) showed that oil prices contributed substantially to U.S. inflation before 1981, but since that time the pass-through has been much smaller. Similar results have been found for other advanced economies and for some emerging market economies. The decline in pass-through is attributable to the reasons above that explain how monetary policy may have helped create a regime where inflation is less sensitive to price shocks. Following this strand of the literature, many studies provide evidence that the adoption of inflation target (IT) is associated with an improvement in overall economic performance (Bernanke and Mishkin (1997); Svensson (1997)) and has even attenuated the oil pass-through (Mishkin (2007)). A more recent literature, however, finds that the inflation targeting regime is not a major determinant of the degree of pass-through (see Choi, et al. (2018)).

Regarding the asymmetric OPT, the notion that upward cost shocks are passed through faster than downward cost shocks is usually explained under a non-competitive market framework. In particular, when the global oil price rises, domestic petroleum enterprisers will increase their refined oils prices as soon as they can in order to maintain their regular profit margins and not to experience any losses. Since the refined oils are inputs and the raw materials of a variety of industrial products, production cost of several products will increase, pushing up producer and consumer prices (PPI and CPI, respectively). On the contrary, when refiners or re-tailers experience a decline in their input costs, they will do not rush to decrease accordingly wholesale or retail prices, since they can take advantage of the additional profits they can make. This means that the decline of PPI and CPI is also smaller too. This asymmetric price adjustment, introduced first by Bacon (1991) to explain the UK retail gasoline 
market, is known as the "rockets and feathers' effect", because prices rise like a rocket, but fall like a feather. Moreover, monetary authorities perceive differently positive and negative oil prices shocks: whereas central banks may welcome falling oil prices if they ease inflation and boost growth, they may be more reluctant to let pass oil price boosts to producer and consumer prices.

In this paper we bring together these two strands of the literature by studying the role of inflation targeting on the OPT. We adopt two alternative methodologies to ensure the robustness of our results. First, we estimate by dynamic GMM a standard pass-through equation that allows for different responses to positive and negative oil price changes that we interact with dummy variables for inflation target. Second, we estimate time-varying pass-through coefficients by means of state-space models. We then test the predictions that IT has reduced the impact of oil price shocks into inflation using a well-established empirical framework that allows to control for endogeneity and self-selection bias, namely a propensity score matching (PSM) methodology. We privilege this approach since, rather than putting forth yet another empirical model for the inflation with interaction variables, the PSM methodology allows to determine whether a treatment, i.e. inflation target, leads to different outcomes than the absence of treatment, by matching treated observations with control observations that share similar characteristics other than the presence of the treatment. That is, we construct a counterfactual for the treatment, based on a set of observable characteristics to guarantee that we are comparing the "comparables" (see Lopez-Villavicencio and Pourroy (2017)). Furthermore, we distinguish between oil prices increases and decreases and contrast the results in each case. Finally, we estimate different models and use several alternative definitions in order to ensure the robustness of our findings.

Our empirical results shed new evidence regarding the impact of inflation targeting: contrary to conventional wisdom, economies with IT have a higher pass through than economies without this monetary regime. However, our main contribution is to show that this results holds only for oil price decreases. The fact that both oil prices increases and decreases impact inflation in ITers reduces the asymmetry of the pass-through. Indeed, a $10 \%$ drop in oil price leads about a $0.11 \%$ drop in inflation in ITers (of which $4 \mathrm{pp}$ are explained by the monetary regime). Our results seem to show that that IT countries always react to oil price increases while non-IT countries do react only when inflation is high, the cost of inflation being clearly higher than the cost of a restrictive policy. On the contrary, decreasing oil price are used mainly by IT central banks to reduce inflation and to bring it closer to the target. A possible explanation for these results is that IT central banks pursuit a more systematic policy than non-ITs: they follow a Taylor rule, and respond systematically and symmetrically to shocks, so the asymmetry of the PT is lower. In sum, falling 
oil prices seem to be more welcomed by the central banks with an IT framework, in particular during deflationary episodes or when inflation is above the target.

The rest of the paper is organized as follows. Section 2 describes in detail our methodology. Section 3 presents the data. Section 4 displays our estimation results obtained by both approaches. Robustness exercises are presented in Section 5 . Section 6 concludes the paper.

\section{The econometric framework}

Our model of the oil pass-through is based on the following generic specification:

$$
\Delta p_{i, t}=\alpha_{i}+\sum_{j=1}^{n} \gamma_{j} \Delta p_{i, t-j}+\beta \Delta p o i l_{i, t}+\theta \Delta e_{i, t}+\rho \Delta y_{i, t}+\lambda \Delta p_{i, t}^{*}+\epsilon_{i, t}
$$

where $p_{i, t}$ denotes consumer prices in period $t$ for country $i$, poil is the international price of oil, $\alpha_{i}$ is a country fixed-effect, $e$ is the nominal effective exchange rate, $y$ is the demand shifter, $p^{*}$ corresponds to a supply shock variable and $\epsilon$ is an independent and identically distributed error term. ${ }^{1}$ Equation (1) is estimated using the dynamic GMM methodology. All the variables are expressed in logarithms.

Note that in Eq.(1), the OPT coefficient, $\beta$, is assumed to be symmetric. To analyze the asymmetric effects, we further decomposed price changes into its positive and negative variations as:

$$
\Delta \text { poil }_{t}^{+}=\left\{\begin{array}{ll}
\Delta \text { poil }_{t}, & \text { if } \Delta \text { poil }_{t}>0 \\
0, & \text { otherwise }
\end{array} ; \Delta \text { poil }_{t}^{-}= \begin{cases}\Delta \text { poil }_{t}, & \text { if } \Delta \text { poil }_{t}<0 \\
0, & \text { otherwise }\end{cases}\right.
$$

were poil $_{t}^{+}$and poil $l_{t}^{-}$represent an increase and decrease in the oil price, respectively. Therefore, the asymmetric OPT equation is the following one:

$$
\Delta p_{i, t}=\alpha_{i}+\sum_{j=1}^{n} \gamma_{j} \Delta p_{i, t-j}+\beta^{+} \Delta p o i l_{i, t}^{+}+\beta^{-} \Delta p o i l_{i, t}^{-}+\theta \Delta e_{i, t}+\rho \Delta y_{i, t}+\lambda \Delta p_{i, t}^{*}+\epsilon_{i, t}
$$

The previous distinction between positive and negative changes is important for at least two reasons. First, the impact on inflation is not necessarily of the same magnitude for positive and negative changes. Second, oil price increases and decreases are not perceived in the same way by monetary authorities. Indeed, traditionally, most central banks admit that higher crude prices help boost inflationary pressures

\footnotetext{
${ }^{1}$ We include 4 lags of the inflation rate to better capture the observed inertial behavior of inflation (inflation persistence) and to avoid underestimating the pass-through.
} 
in the near-term, possibly providing second-round inflationary effects and filtering into higher inflation expectations. More recently, however, positive oil price shocks are consider not as inflationary as they used to be, allowing a less aggressive monetary policy response. On the contrary, falling oil prices are more welcome as they could ease inflation - especially core inflation or expectations - in which case central banks may respond with monetary loosening which, in turn, can boost activity. ${ }^{2}$

Since we are interested in the impact of adopting the monetary regime on the ERPT, we further interact the change in oil prices with a dummy variable that takes on the value one starting in the period in which the country adopted this inflation target (and for all subsequent years), and zero otherwise. The model in this case is the following one:

$$
\begin{aligned}
\Delta p_{i, t}= & \alpha_{i}+\sum_{j=1}^{n} \gamma_{j} \Delta p_{i, t-j}+\beta^{+} \Delta \text { poil }_{i, t}^{+}+\beta^{-} \Delta p o i l_{i, t}^{-}+\phi I T_{i, t} \\
& +\delta^{+}\left(\Delta \text { poil }_{i, t}^{+} \times I T_{i, t}\right)+\delta^{-}\left(\Delta p o i l_{i, t}^{-} \times I T_{i, t}\right)+\theta \Delta e_{i, t}+\rho \Delta y_{i, t}+\lambda \Delta p_{i, t}^{*}+\epsilon_{i, t}
\end{aligned}
$$

To provide a complete analysis, and in order to overcome endogeneity issues, as a second exercise we allow for time-varying OPT coefficients that we use latter to match observations with and without the monetary target. More in detail, by employing state space models we estimate the oil pass-through coefficients for each country and period of the sample. State-space models are based on the idea that we can use the observations to estimate the underlying states, which are unobserved. The usual oil pass-through equation with the observation equation and the state equation allows the coefficient of pass-through to vary over time. Therefore, for each country in the sample, we use the time series equivalent of Eq. (2), i.e. the measurement equation, with the following OPT shift equation:

$$
\begin{aligned}
& \beta_{t}^{+}=\theta_{t-1}^{+}+C v_{t} \\
& \beta_{t}^{-}=\theta_{t-1}^{-}+C v_{t}
\end{aligned}
$$

where the OPT parameter $\beta_{t}^{+}$and $\beta_{t}^{-}$are time-varying and depend on an autoregressive term and $v_{t} \sim N\left(0, Q_{t}\right)$. The system (2)-(4) constitute our state-space

\footnotetext{
${ }^{2}$ Note that monetary authorities may also respond differently to demand and supply shocks in oil markets. On the supply side, lower oil prices lead to a decline in the cost of production that may be passed on to consumers and hence, indirectly, reduces inflation. The lower cost of production can also translate in higher investment. On the demand side, a decline in oil prices raises consumers' real income and leads to an increase in consumption and maybe inflation. See Kilian and Park (2009) and Kilian and Lewis (2011).
} 
model. These type of models can be estimated using the Kalman filter recursive algorithm, which is commonly employed in time-varying coefficient models. The Kalman filter is a method for recursively obtaining linear, least-squares forecasts of unknown coefficients conditional on past information. These forecasts are used then to construct the log likelihood. More precisely, for each time $t$, the Kalman filter produces a conditional expected state vector and a conditional covariance matrix; both conditional on information up to and including time $t .{ }^{3}$

We next assess the effect of an explicit inflation target with propensity score matching. Specifically, we properly control for endogeneity and self selection bias to asses if countries that have adopted IT present a lower level of OPT than countries that have not. Adopting an IT framework is not a random event. Due to self selection bias, a difference in OPT between countries with IT and the other countries could then be attributable to systematic differences in some variables between the two groups of countries rather than the effect of IT adoption. Also, adopting an IT framework may be seen as an endogenous choice (see Mishkin and Schmidt-Hebbel (2001)). For instance, countries with histories of high inflation or expecting future high inflation are more likely to have felt compelled to adopt IT. The finding that OPT is associated with IT thus may not imply that IT causes the OPT. Therefore, in order to ensure that the difference in OPT between countries faced with IT and the other countries is attributable to the treatment itself (IT adoption), and not to systematic differences in some variables, we employ the matching and propensity score methodology that was developed precisely for the bias associated with this type of estimation problem.

The idea behind the PSM approach is to determine whether a treatment leads to different outcomes than the absence of treatment, by matching treated observations with control observations that share similar characteristics other than the presence of the treatment. Following the matching of observations, we assess the "treatment effect" by measuring the difference in the OPT between the two groups. That is, we see IT adoption as a "natural experiment," so we seek to reestablish the conditions of a randomized experiment where the IT adoption mimics a treatment.

In particular, let $D$ be a binary indicator that equals one if a country has adopted IT and zero otherwise. Also, let $Y_{i}^{1}$ denote the OPT for country $i$ if the country has adopted IT (i.e. if the country is in the treated group) and $Y_{i}^{0}$ if not, all other characteristics of the country being equal. The treatment effect for country $i$ can be written as $Y_{i}^{1}-Y_{i}^{0}$, where one outcome is observed and the other one is the counterfactual. We are interested in estimating the average treatment (ATT) effect on the treated countries, that is:

\footnotetext{
${ }^{3}$ See Lopez-Villavicencio and Pourroy (2017) for further details.
} 


$$
A T T=E\left[Y_{i}^{1} \mid D=1\right]-E\left[Y_{i}^{0} \mid D=1\right]
$$

Introducing the control group, we can write the average treatment as:

$$
A T T=E\left[Y_{i}^{1} \mid D=1\right]-E\left[Y_{i}^{0} \mid D=0\right]-E\left[Y_{i}^{0} \mid D=1\right]+E\left[Y_{i}^{0} \mid D=0\right]
$$

where $E\left[Y_{i}^{1} \mid D=1\right]$ and $E\left[Y_{i}^{0} \mid D=0\right]$ are observed and $E\left[Y_{i}^{0} \mid D=0\right]-E\left[Y_{i}^{0} \mid D=1\right]$ is the selection bias. Hence, Eq.(6) can only be identified if this selection bias disappears, i.e. if $E\left[Y_{i}^{0} \mid D=1\right]=E\left[Y_{i}^{0} \mid D=0\right]$. The PSM methodology deals with this selection problem by pairing each treated observation with control observations that are otherwise similar based on a set of observable characteristics, $\mathbf{X}$. This requires that the treatment satisfies the so-called conditional independence assumption. This assumption states that, conditional on a vector of observable characteristics, the variable of interest (the OPT) is independent of the treatment status. Conditional on this vector $\mathbf{X}$, the expected OPT in the absence of IT would then be the same for paired countries, that is $E\left[Y_{i}^{0} \mid D=1, \mathbf{X}\right]=E\left[Y_{i}^{0} \mid D=0, \mathbf{X}\right]$, and the bias would disappear. Under this assumption then ATT effect is written as:

$$
A T T=E\left[Y_{i}^{1} \mid D=1, \mathbf{X}\right]-E\left[Y_{i}^{0} \mid D=0, \mathbf{X}\right]
$$

In Eq. (7) $E\left[Y_{i}^{1} \mid D=1, \mathbf{X}\right]$ controls for the relevant set of characteristics, $\mathbf{X}$. This set should include variables that are co-determinants of both IT (the treatment) and OPT (the outcome), and conditioning on all relevant variables may be a challenge.

To obtain ATT, we proceed in two steps. We first estimate the propensity score by a benchmark logit equation explaining the likelihood of a country receiving the treatment. To this end, we consider a number of potential structural, political, and economic determinants of IT (or any other treatment).

We then use a matching algorithm to pair the observations based on observable characteristics. Applying these matching methods requires that two hypotheses must be satisfied. The first is the conditional independence assumption stating that, conditional to the vector of observable variables $\mathbf{X}$, the outcome variable is independent of the IT adoption. The second is the common support condition, which ensures that there is sufficient overlap in the characteristics of the treated and untreated groups to find adequate matches.

\section{Data and descriptive statistics}

We consider a sample of 49 advanced and emerging economies that have and have not adopted explicit, i.e. strict, IT between 1980 and 2017 Argentina, Australia*, Austria, Belgium, Brazil*, Canada*, Chile*, China, Colombia*, Czech Rep.*, Denmark, 
Estonia, Finland*, France, Germany, Greece, Hong Kong, Hungary*, Iceland*, India, Indonesia*, Ireland, Israel*, Italy, Japan, Korea*, Latvia, Lithuania, Malaysia, Mexico*, Netherlands, New Zealand*, Norway*, Philippines*, Poland*, Portugal, Romania*, Russia, Singapore, Slovak Rep.*, Slovenia, South Africa*, Spain, Sweden*, Switzerland*, Thailand*, Turkey*, The United Kingdom* and The United States. Therefore, from our 49 countries, 26 countries are ITers. ${ }^{4}$

The variables entering the estimation of the oil pass through are: (i) the consumer price index $(P)$, (ii) the West Texas Intermediate Crude Oil price, (iii) the nominal effective exchange rate defined as domestic currency per unit of foreign currency ( $E$, source BIS), (iv) the GDP ( $Y$, source IFS), and (v) the OECD producer price index as a proxy for supply factors $\left(P^{*}\right.$, source OECD). ${ }^{5}$ All the series are seasonally adjusted. We work with the year-to-year differences of the variables expressed in logarithm terms.

For the second step, namely, the PSM estimation, we work with annual data in order to consider a broad set of variables that define an economy. We therefore annualised the OPT found in the first step by taking the annual mean value of the four quarters.

Regarding the variables related to inflation targeting, we use a dummy variable $I T$ that takes on the value one starting in the period in which the country adopted this inflation target (and for all subsequent years), and zero otherwise. According to Mishkin (2004) or Hammond (2012), a central bank has an IT framework if it fullfills the five following criteria : 1) Price stability is explicitly recognized as the main goal of monetary policy; 2) There is a public announcement of a quantitative target for inflation; 3) Monetary policy is based on a wide set of information, including an inflation forecast; 4) Transparency; and 5) Accountability mechanisms. For the sake of robustness, we follow Rose (2007), Minea and Tapsoba (2014) and Balima, Combes, and Minea (2017) and distinguished between Full-fledge (FF from now on) and Soft starting dates of IT. The difference between the two dates captures the fact that some central banks first adopted "soft or informal" IT (see Vega and Winkelried (2005)), in which the central bank's reaction, following a deviation of inflation from its targeted level, is slower compared to its reaction under an explicit "full-fledged or formal" IT. Consequently, soft IT are those dates declared by central banks

\footnotetext{
${ }^{4}$ Countries with an explicit IT framework are denoted with a star $(*)$. Dates of adoption are presented in Table (8) in the Appendix.

${ }^{5}$ Although exchange rate and oil price shocks have the advantage of being relatively easier to quantify, it is more difficult to measure precisely other forms of foreign costs, since they are often not directly observable. As a result, researchers proxy these costs from different sources: foreign producer price index, foreign output gap, etc. We follow Gopinath, Itskhoki, and Rigobon (2010) and analyze the pass-through with Eq.(1), where foreign marginal costs are proxied by foreign PPI. Our choice of averaging over OECD countries is justify by data availability as well as the share of the OECD share of trade in total trade.
} 
themselves, while full-fledged IT starting dates are those considered by academia as the genuine dates from which the central bank began meeting the required criteria to be classified as an ITer. Our sources are Rose (2007), Roger (2009) and Minea and Tapsoba (2014). ${ }^{6}$

The rest of the variables correspond to the controls that we use in the logit estimations: inflation volatility, financial development (captured by World Bank broad money series), exchange rate regime (using Ilzetzki, Reinhart, and Rogoff (2017) classification), and the share of fuel in imports and in energy consumption (by the World Bank) are the set of variables entering the benchmark logit model for the propensity score for inflation targeting. Appendix A reports the exact definition and source of all the variables.

\section{Results}

In this section we present the results of the benchmark estimation (Eq.1). We further expand our analysis to allow for an asymmetric pass-through and estimate the impact of adopting inflation target. In the second part, we allow for time-varying coefficients for the time series and present the difference in OPT by considering the role of the adoption of an inflation target as a treatment to find suitable counterfactuals to the actual targeters, i.e., using propensity score matching. Finally, we conduct a detailed analysis related to different forms of IT.

\subsection{Panel estimation}

Table 1 presents the GMM pass-through coefficients of Equations (1) and (2). As seen, the significant positive coefficient shows that changes in oil prices have a strong effect on inflation in most cases even though this relationship varies widely across countries. $^{7}$

More precisely, we find that a 10\% change in global oil inflation increases domestic inflation by about $0.13 \%$ in average. However, looking at the results presented in the third and fourth lines of the table clearly shows an asymmetric impact of oil

\footnotetext{
${ }^{6}$ Note that the definition of IT is quite restrictive. Indeed, for inflation targeters, price stability is the main goal of central bank's mandate. Therefore, the USA and countries at the EMU are not consider as ITers. Indeed, the Fed has a dual mandate with two goals: price stability and maximum sustainable employment. Moreover, until January 2012 the Fed had not announced a quantitative target for inflation. The European Central Bank, in turn, has a hierarchical mandate that makes price stability the primary objective. However, in the implementation of its policy, the ECB follows a two pillar approach that focus on all information (real sector activities and monetary aggregates developments) and not only on price developments.

${ }^{7}$ For completeness, we present in table 1 in the Appendix the results for each country of the sample.
} 
price movements: positive oil price shocks have a larger effect than negative ones, the difference being statistically significant.

Table 1: Symmetric and asymmetric oil pass-through coefficients.

\begin{tabular}{|c|c|c|}
\hline \multirow[b]{2}{*}{$\Delta$ poil } & Coeff. & (t-stat) \\
\hline & 0.013 & 3.97 \\
\hline$\Delta$ poil $^{+}$ & 0.016 & 5.07 \\
\hline$\Delta p^{\prime} i_{l}^{-}$ & 0.008 & 2.31 \\
\hline$\beta^{+}=\beta^{-}$ & & \\
\hline
\end{tabular}

Notes: (a) This table shows the dynamic GMM panel estimation results of Eq. (1) and (2); (b) $\beta^{+}=\beta^{-}$is the $\chi$-test probability for the Wald test.

Given this asymmetric aspect of the oil pass-through, we proceed to estimate the effects of the IT monetary regime on the positive and negative changes of oil prices by interacting the asymmetric coefficients with the IT dummy variable. Results, presented in table 2 , show that a rise in oil price increases domestic inflation independently of the adoption of IT, the interaction variable with the positive change not being significant. However, a drop in oil prices does not lead to a drop in inflation in non ITers. Indeed, the non significance of the coefficient for negative changes and its significance when interacted with negative changes indicates that the fall in the pass-through occurs in this case only for countries with the monetary target. Therefore, these values seem to indicate that ITers have a less asymmetric oil price change pass-through to consumer inflation than non-ITers.

Table 2: Effects of IT on asymmetric oil pass-through.

\begin{tabular}{lcc}
\hline & Coeff. & (t-stat) \\
\cline { 2 - 3 }$\Delta$ poil $^{+}$ & 0.021 & $(4.16)$ \\
$\Delta$ poil $^{+} \times I T$ & -0.012 & $(0.58)$ \\
\cline { 2 - 3 } poil $^{-}$ & 0.003 & $(0.58)$ \\
$\Delta$ poil $^{-} \times I T$ & 0.019 & $(2.14)$ \\
\hline
\end{tabular}

Notes: This table shows the dynamic GMM panel estimation results of Eq. (3)

\subsection{Propensity score estimates}

Our analysis would not be complete without controlling for self-selection bias and endogeneity. Indeed, we need to isolate what is due to the monetary regime from what is due to country specific characteristics. In order to do so, we now turn to 
the propensity score estimate. As long as we are aware of, this methodology has not been used before to account for oil pass-through.

Once the symmetric and asymmetric time-varying oil price pass-through is calculated using state-space models, it remains to asses the impact of adopting an inflation targeting framework. As a first glance, Figures 1-3 in the Appendix show the evolution PT coefficients and the date of the adoption of IT, when relevant.

For a more formal examination, using these coefficients, we next follow a three steps procedure: first we compute the propensity score, then we match the propensity score of the treated and control groups, last we compute the average treatment effect.

The propensity score is obtained by estimating the probability of observing IT for all the countries of our sample, using a logit model where IT is the independent variable. To respect the conditional independence assumption, the propensity score estimates should include the possible variables that may have a systematic impact on the choice of adopting IT. ${ }^{8}$ We next proceed to verify that the independence condition holds, i.e., that the value of various control variables does not significantly differ between the treatment and control groups once the matching is computed. ${ }^{9}$ The results using different matching algorithms, presented in table 3 , indicate that no significant difference remains in the data after completed the matching procedures. ${ }^{10}$ We end-up with six exogenous variables that capture institutional environment (Polity2), financial development (Money), inflation volatility (Inflation Vol.), exchange rate regime (Regime), and the share of fuel in imports (Import) and energy consumption (Fossil). Definitions and sources are presented in Appendix A.

\subsubsection{Average treatment effect of Inflation Targeting on the pass-through}

Having validated the first two steps (propensity score estimation and matching treated and untreated observation), we estimate the impact of IT adoption on the oil price pass-through to inflation. The average treatment effects (ATT) is presented

\footnotetext{
${ }^{8}$ Note that we estimate a logit model in order to orthogonalize a set of covariante variables into a single dimension rather than to to explain IT. Hence, as opposed to a classic logit estimation, our list of exogenous variables should not deliver the best statistical model to explain the probability of IT adoption but rather it should be a set of variables that explains IT(with possibly some variables that also have a systematic impact on OPT as well, since adopting IT may be endogenous to the OPT) and respects the conditional independence assumption.

${ }^{9}$ During the matching step, we exclude data outside the "common support", that is observations from the control group with PS lower than the minimum PS in the treated group as well as observations from the treated group with PS higher than the maximum PS in the control group.

${ }^{10}$ The standardized percentage bias, i.e. the average gap between the Treated and Control group expressed as a percentage of the square root of the sample variance, has been reduced by more than $80 \%$ due to the matching process, resulting in a bias after matching (R\&R's Residual Bias) of less than $5 \%$, which is small enough to accept the absence of conditional dependence.
} 
in table 4.2, using five matching algorithms. Standard errors are based on bootstrap resampling with 500 replications.

Considering symmetric oil pass-through, the results in the table show that IT significantly increases the PT: the average treatment effect (IT adoption) is positive and significant. ${ }^{11}$ Indeed, depending on the matching algorithm and the control variables considered, the increase is estimated to lie between 0.00129 and 0.00189 percentage points. ${ }^{12}$ This result may appear surprising because countries adopt IT as a framework to keep inflation under control. Typically, a country adopts IT to avoid that global shocks translate into large domestic inflation. This result may lead us to conclude that IT does not deliver the expected results, and is not efficient in stabilizing prices.

However, in order to avoid any premature conclusion, it is important to scrutinize differences with respect to oil price increases and decreases. Our results in table 4 confirm that, faced with oil price increases, the existence of inflation targeting regimes does not seem to be a major determinant of the degree of pass-through $\left(\mathrm{OPT}^{+}\right) .{ }^{13}$ In fact, our results reveal that the positive difference between ITers and non ITers is entirely due to larger inflation decline in IT countries when the oil price declines, the ATT being negative and significant in this case $\left(\mathrm{OPT}^{-}\right)$. The average treatment effect is around 0.004 . In other words, while a $10 \%$ oil price falls leads to a $0.11 \%$ consumer price decrease in IT countries, it would lead to a $0.07 \%$ consumer price decrease in the same countries without IT. These results may suggest that falling oil prices are more welcomed by the central banks pursuing inflation target.

Finally, it is worth noting that if IT makes the pass-through stronger when oil prices fall, then it reduces the asymmetry of the PT. The asymmetry comes from the fact that the $\mathrm{PT}$ on the rise is stronger than the $\mathrm{PT}$ on the downside, but for the ITers the PT on the downside is higher than for the non-ITers. Consequently the asymmetry is lower for ITers than for non-ITers. Let $a_{i}$ to denote the average asymmetry between the estimated pass-through when oil price increases and when oil price decreases. For a given country $i$ we have $a_{i}=\beta_{i}^{+}-\beta_{i}^{-}$. It can easily be shown that the average treatment effect of IT on the pass-through asymmetry is equal to the difference between the ATT when oil price increases and the ATT when

\footnotetext{
${ }^{11}$ For the sake of robustness, we estimate the average treatment effect for the "Soft IT" classification adoption date and we add variables related to the structure of the economy, the financial sector or the fiscal position of the country while computing the PS index (see Balima, Combes, and Minea (2017)). The estimated ATT in both cases are similar to the baseline estimation. All the results are available upon request to the authors.

${ }^{12}$ In other words, while a $10 \%$ oil price change leads to a $0.13 \%$ consumer price change in IT countries, it would lead to a $0.11 \%$ consumer price decrease in the same countries without IT.

${ }^{13}$ Based on a symmetric and static framework, Gelos and Ustyugova (2017) or Choi, et al. (2018) present evidence that IT is not the main determinant for the OPT.
} 
oil price decreases: 14

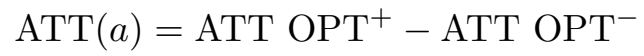

Based on results in table 4, adopting IT reduces the asymmetry of oil price change pass-through to consumer inflation by about 40bps in average.

\subsubsection{Explaining oil price PT to inflation when oil price increases}

To understand what may be behind our previous results, we estimate the effect of IT for different inflation levels. Results are presented in table 5.

Let us first focus on increasing oil price episodes. When inflation is lower than $3 \%$, IT countries have indeed a lower pass-through than non ITers, the ATT being negative and significant. However, when inflation is higher, IT and non-IT countries have similar pass-through to inflation.

A possible explanation is that IT countries always react to oil price increases while non-IT countries do react only when inflation is high. For example, when inflation is low, non-IT countries may not want to react to oil prices by tightening monetary policy, the cost of inflation being lower than the growth lost cost caused by policy tightening. For an IT central bank, even at low inflation, oil price increases may induce a deviation from the target and hence being costly enough (in terms of credibility or more broadly preferences) to justify a tightening policy. However, for inflation higher than $5 \%$, there is no difference between IT and non-IT countries. One possible explanation is that when inflation is high, all central banks react, the cost of inflation being clearly higher than the cost of a restrictive policy. In other words, our candidate explanation is based on preferences. IT central banks seem to be, in average, more conservative than non-IT central banks: an IT central bank may give an higher weight in their implicit cost function to inflation than do non-IT central banks. ${ }^{15}$ To test this hypothesis, we estimate the average treatment effect (ATT) excluding either the most conservative or the less conservative central bank. Results are show in table 5 .

\footnotetext{
${ }^{14}$ The average treatment effect (ATT) of the treatment (inflation targeting, IT=1) relatively to the control group $(\mathrm{IT}=0)$ on the oil price change pass-through to consumer inflation asymmetry $\left(a_{i}=\frac{1}{T} \sum_{t=1}^{T} \beta_{i, t}^{+}-\frac{1}{T} \sum_{t=1}^{T} \beta_{i, t}^{-}\right.$is equal to the difference between the ATT when oil price increases and the ATT when oil price decreases:

$$
\begin{aligned}
\operatorname{ATT}(a) & =E\left[a_{i} \mid I T=1, \mathbf{X}\right]-E\left[a_{i} \mid I T=0, \mathbf{X}\right] \\
& =E\left[\left(\beta_{i}^{+}-\beta_{i}^{-}\right) \mid I T=1, \mathbf{X}\right]-E\left[\left(\beta_{i}^{+}-\beta_{i}^{-}\right) \mid I T=0, \mathbf{X}\right] \\
& =E\left[\left(\beta_{i}^{+} \mid I T=1\right)-\left(\beta_{i}^{+} \mid I T=0\right), \mathbf{X}\right]-E\left[\left(\beta_{i}^{-} \mid I T=1\right)-\left(\beta_{i}^{-} \mid I T=0\right), \mathbf{X}\right] \\
& =\operatorname{ATT}\left(\beta^{+}\right)-\operatorname{ATT}\left(\beta^{-}\right)
\end{aligned}
$$

${ }^{15}$ Most (least) conservative central bank are those ranked over (below) the median in the Central Bank Conservatism index (cons) by Levieuge, Lucotte, and Pradines-Jobet (2019).
} 
Consistently with the explanation above, we find that most conservative IT central banks, with a relatively higher preference for price stability than output, have a lower PT than non-IT central banks: it is likely that conservative IT central banks react stronger to oil price increases, hence reducing the pass-through to inflation. Last, we find that the least conservative IT central banks have an average oil price PT to inflation similar to non-IT central banks. These results seem to confirm that the positive impact of being an IT country on non-IT oil price change pass-through to consumer inflation, observed when inflation is low, is due to a more conservative preferences by IT central banks, likely to imply stronger central bank reaction.

\subsubsection{Explaining oil price PT to inflation when oil price decreases}

Turning to decreasing oil price episodes, table 4 shows that, when oil prices decrease, consumer prices decrease significantly more in IT countries than in non-IT countries, the ATT for $\mathrm{OPT}^{-}$being close to 0.4 base points, in average.

A first explanation could be that decreasing oil price are used by IT central banks to reduce inflation and to bring it closer to the target. To test this assumption we divided our IT sample into three groups: i) inflation close to the target, ii) above the target and, iii) below the target. ${ }^{16}$ Results display on table 6 seem to validate this explanation. The positive effect of IT on oil PT is not observed when inflation is below the target. In this situation, IT and non-IT countries are similar. However, when inflation is close to the target or above, IT countries are more accommodative to negative oil prices than non-IT countries.

A second explanation could be that IT central banks do not have the same ability as non-IT central banks to tackle lowering prices. Typically, IT central banks generally use the interest rate as their main policy instrument, while non-IT central banks could be more incline to foreign exchange rate interventions, credit controls, stock market operations, etc. Consequently, if the zero lower bound is seen as a risk, IT central banks may appear less credible in their ability to face deflationary pressures. To test this hypothesis, we consider that if IT central banks had not the ability to respond to deflationary pressure, then there should be no impact of central bank preferences on the pass-through. We show in table 6 the ATT excluding from the sample central banks based on their preferences. We find that the most conservative central banks have a lower ATT value than the least conservative. This means that when central banks give a high weight to price stability, they can reduce the impact of oil prices on inflation. Therefore, the positive ATT associated to IT is not an ability issue but more about a wish.

Our third and last explanation could be that IT central banks have non strictly symmetric targets : IT central banks react strongly when facing increasing price

\footnotetext{
${ }^{16}$ We considered inflation to be close to the target if it is within a $25 \%$ band around the target.
} 
(stronger than non-IT) but their answer is weak when facing decreasing prices (weaker than non-IT) simply because they welcome negative price shocks. To illustrate this point, recall that IT was generally adopted at a time when high inflation was much more a concern for central bankers than deflationary pressures. In the recent years, ITers motivation to adopt IT was generally the opposite to the Fed: when the Fed announced a $2 \%$ target in 2015 , the purpose was to drive inflation up to $2 \%$ and to avoid deflationary expectations by markets participants. Consequently, the FOMC had to precise in 2017, when the target was almost reached, that it was a symmetric target, and not a ceiling rate. ${ }^{17}$ The situation of most ITers is at odd: they adopted a target as a commitment to price stability and in order to anchor inflation expectation at a lower level than it used to be. ${ }^{18}$ Consequently, Roger and Stone (2005) consider that IT starts with a "Disinflation Phase" followed by a "Stationary Inflation Target Phase". One can thus think that ITers are compliant with deflationary shocks, even if they drive inflation slightly below the target (the target can subsequently be revised downwards). To test this hypothesis, we calculate ATT excluding countries that experience IT for more than 3 years. Results are shown in table 6 and are consistent with the idea that ITers are more likely to welcome negative oil prices when they are still in the early stage of IT: the older the IT framework, the lower the treatment effect (ATT).

\section{Robustness}

In this section we conduct a series of exercises to ensure the robustness of our results. First, we changed in our benchmark PSM presented in Table 4 the measure of oil prices. First, following Baumeister and Kilian (2011) we use the U.S. Crude Oil Imported Acquisition Cost by Refiners (Dollars per Barrel) as a measure of world oil price. Second, as suggested by Kilian and Park (2009) we estimate the main equation with real oil price instead of the nominal one. The table also shows the results when all the variables in Eq. (1) are lagged. As seen in table 10, our results are robust in the three cases.

Moreover, in order to prevent our estimates from being distorted by the zero

\footnotetext{
${ }^{17}$ This appears in the Minutes of the Fed Meeting of March 14-15, 2017: "A few members expressed the view that the Committee should avoid policy actions or communications that might be interpreted as suggesting that the Committee's 2 percent inflation objective was actually a ceiling. Several members observed that an explicit recognition in the statement that the Committee's inflation goal was symmetric could help support inflation expectations at a level consistent with that goal, and it was noted that a symmetric inflation objective implied that the Committee would adjust the stance of monetary policy in response to inflation that was either persistently above or persistently below 2 percent." Minutes of the Meeting of March 14-15, 2017, page 11. https://www.federalreserve.gov/monetarypolicy/files/fomcminutes20170315.pdf

${ }^{18}$ Moreover, in many cases, a central banks' mandate was only about "price stability", the target being a mean (and inflation targeting a framework) to achieve the objective of price stability.
} 
lower bound and the limits of the central bank to react in this case, we estimate the models excluding the 2008-2017 period, i.e. after the Great Recession. Second, we excluded the period 2014-2017. Indeed, following four years of relative stability at around 105 dollars per barrel, oil prices have declined sharply since June 2014. Even though it is not the first sharp oil price swing, it was accompanied by slowing global growth, with lower oil prices cushioning, but likely not reversing, the growth slowdown. As revealed in table 7, the main conclusions are quite similar for all the sub-periods.

Additionally to the monetary goal, we could expect different reactions among oilimporting and exporting countries. For instance, in oil-importing countries, lower oil prices due to an adverse shock to the level of global economic activity, would act as a gain in real disposable income for consumers, which in turn could be either saved or spent, mitigating some of the negative impact of the initial demand shock. On the contrary, adverse demand shocks that reduce the price of oil negatively affect spending among commodity exporters. Moreover, an exogenous increase in the supply of oil that reduces prices, however, would be expected to boost global GDP in both producer and consumer countries. We therefore estimate the models excluding oil exporters. Results in table 7 remain very close to the baseline.

Finally, it is suggested that energy subsidies are an important determinant of the oil pass-through. In particular, according to Choi, et al. (2018), a country with a high level of energy subsidy is likely to have a lower inflationary impact from global oil price shocks. Moreover, an administered price system or price regulations can also offer a mechanism to cushion the international price changes and achieve domestic policy objectives on inflation (see Bhanumurthy, Das, and Bose (2012)). We explore this possibilities by excluding countries with a large proportion of prices are administered. ${ }^{19}$ As seen in table 7 , excluding countries with energy subsidies or administered prices does not change the ATT of IT.

\footnotetext{
${ }^{19}$ We rely on CEPII IPD measure (B4040) that includes a measure of direct commodity price and gasoline subsidies. A country is assumed to have a large proportion of administered prices if its score is greater than the median.
} 


\section{Conclusions}

In this paper we investigate the role of inflation targeting in the relationship between oil price movements and domestic inflation. More in detail, we propose two approaches to account for the role of IT on the pass-through. First, we interact oil price changes with a dummy for IT. Second, we estimate varying coefficients and consider the adoption of an inflation targeting framework by a country as a treatment to find suitable counterfactuals to the actual targeters. In addition, we allow for the possibility that inflation responds differently to price increases than decreases.

Consistently with the literature, we find evidence of pass-through asymmetries. Our main contribution is to show that the monetary regime has an impact on both the pass-through and the asymmetry. By controlling for self-selection bias and endogeneity, we show that the adoption of inflation targeting increases the passthrough for oil price decreases and therefore reduces the asymmetry.

More precisely, our main results are as follow: (1) when oil price increases and consumer inflation remains low, the pass-through is lower in IT countries, consistent with conservative preferences; (2) when oil price increases and consumer inflation is high, we do not find any difference between IT and non-IT countries; (3) when oil price decreases, the pass-through is significantly larger in IT countries. This is particularly observed during deflationary stages or when inflation is above the target.

In sum, because IT is associated to a greater PT when the oil price falls, there is an almost symmetric impact of oil price changes on inflation in these countries. For instance, in both IT countries and non ITers, a $10 \%$ rise in the oil price increases domestic inflation by $0.14 \%$. However, a $10 \%$ drop in oil prices leads to a $0.11 \%$ drop in inflation in countries following inflation target but only a drop of about $0.07 \%$ in inflation for countries with the same characteristics but a different monetary regime. 
Table 3: Conditional independence assumption

\begin{tabular}{|c|c|c|c|c|c|c|c|}
\hline \multirow[b]{3}{*}{ Polity2 } & \multicolumn{2}{|c|}{ Mean } & \multicolumn{5}{|c|}{ P-value (Treated = Control) } \\
\hline & Treated & Control & $\begin{array}{c}\text { Nearest } 1 \\
\text { neighbor }\end{array}$ & $\begin{array}{c}\text { Nearest } 5 \\
\text { neighbor }\end{array}$ & Kernel & $\begin{array}{l}\text { Local- } \\
\text { linear }\end{array}$ & $\begin{array}{c}\text { Radius } \\
\quad(.05)\end{array}$ \\
\hline & & & & & & & \\
\hline Unmatched & 8.8651 & 8.0696 & 0.001 & 0.001 & 0.001 & 0.001 & 0.001 \\
\hline Matched & 8.8343 & 8.8677 & 0.926 & 0.890 & 0.843 & 0.926 & 0.863 \\
\hline \multicolumn{8}{|l|}{ Money } \\
\hline Unmatched & 76.664 & 76.846 & 0.945 & 0.945 & 0.945 & 0.945 & 0.945 \\
\hline Matched & 76.237 & 76.422 & 0.489 & 0.433 & 0.967 & 0.475 & 0.947 \\
\hline \multicolumn{8}{|c|}{ Inflation Vol. } \\
\hline Unmatched & .77422 & 6.4439 & 0.165 & 0.165 & 0.165 & 0.165 & 0.165 \\
\hline Matched & .77947 & .75436 & 0.888 & 0.509 & 0.698 & 0.783 & 0.711 \\
\hline \multicolumn{8}{|l|}{ Regime } \\
\hline Unmatched & 12.724 & 4.9935 & 0.000 & 0.000 & 0.000 & 0.000 & 0.000 \\
\hline Matched & 12.069 & 11.586 & 0.266 & 0.482 & 0.603 & 0.406 & 0.626 \\
\hline \multicolumn{8}{|l|}{ Import } \\
\hline Unmatched & 12.159 & 13.672 & 0.005 & 0.005 & 0.005 & 0.005 & 0.005 \\
\hline Matched & 12.321 & 12.64 & 0.774 & 0.329 & 0.624 & 0.869 & 0.576 \\
\hline \multicolumn{8}{|l|}{ Fossil } \\
\hline Unmatched & 71.318 & 79.288 & 0.000 & 0.000 & 0.000 & 0.000 & 0.000 \\
\hline Matched & 71.737 & 71.617 & 0.087 & 0.407 & 0.859 & 0.213 & 0.939 \\
\hline \multicolumn{8}{|c|}{ All variables } \\
\hline \multicolumn{3}{|c|}{ R\&R's Initial Bias } & 27.9 & 27.9 & 27.9 & 27.9 & 27.9 \\
\hline \multicolumn{3}{|c|}{ R\&R's Residual Bias } & 5.3 & 3.4 & 1.9 & 4.1 & 1.8 \\
\hline \multicolumn{3}{|c|}{ R\&R's Bias Reduction } & 0.81 & 0.88 & 0.93 & 0.85 & 0.94 \\
\hline \multicolumn{3}{|c|}{ Rubin's B } & 15.8 & 12.4 & 7.2 & 12.6 & 7.3 \\
\hline \multicolumn{3}{|l|}{ Rubin's R } & 0.91 & 0.82 & 0.69 & 0.89 & 0.71 \\
\hline
\end{tabular}

Notes: a) The difference between unmatched treated and control is the initial bias. The difference between matched treated and control is, however, minimized during the matching process. The absence of sample bias, i.e. the conditional independence assumption, is validated by testing the difference between the variable average for the treatment group and the control group. In the absence of bias, their should be not significant difference between the two groups means -indicated by a large p-value; b) The R\&R's standardised percentage bias is the average gap between the Treated and Control group expressed as a percentage of the square root of the sample variance; c) The mean (Rubin's B) or variance (Rubin's R) are measures of the average PS gap between the Treated group and Control groups. As a rule of thumb, the balancing hypothesis is accepted for values below 25; d) Rubin's $\mathrm{R}$ is the ratio the Treated group propensity score (PS) index variance to the Control group PS index variance. The acceptance threshold is generally assumed to be from 0.5 to 2 and is validated for our five matching algorithms; e) The treated mean and control mean are reported only for the radius matching algorithm. The balancing hypothesis relies on the covariante variables (polity2, money, inflation vol., regime, import, fossil) and the treatment variable (inflation targeting dummy). The output variable (oil price change pass-through to consumer inflation) has no impact on this test, hence the results are the same for symmetric, positive or negative oil pass-through. 
Table 4: Average treatment effect of IT on oil price change pass-through to consumer inflation.

\begin{tabular}{|c|c|c|c|c|c|}
\hline PSM & $\begin{array}{c}\text { Nearest } \\
\text { neighbor }(1)\end{array}$ & $\begin{array}{c}\text { Nearest } \\
\text { neighbor }(5)\end{array}$ & Kernel & $\begin{array}{l}\text { Local- } \\
\text { linear }\end{array}$ & $\begin{array}{c}\text { Radius } \\
(.05)\end{array}$ \\
\hline \multicolumn{6}{|l|}{ Symetric PT } \\
\hline ATT OPT & $0.00238 * * *$ & $0.00145^{* *}$ & $0.00161^{* * *}$ & $0.00150 * * *$ & $0.00128^{* *}$ \\
\hline T-stat. & $(2.76)$ & $(2.09)$ & $(2.62)$ & $(2.58)$ & $(2.27)$ \\
\hline Treated/Obs. & $341 / 1260$ & $341 / 1260$ & $341 / 1260$ & $341 / 1260$ & $341 / 1260$ \\
\hline \multicolumn{6}{|l|}{ Increase in oil price } \\
\hline $\mathrm{ATT} \mathrm{OPT}^{+}$ & -0.000484 & -0.000652 & -0.000836 & $-0.00122^{*}$ & -0.00101 \\
\hline T-stat. & $(-0.47)$ & $(-0.82)$ & $(-1.02)$ & $(-1.66)$ & $(-1.45)$ \\
\hline Treated/Obs. & $309 / 1151$ & $309 / 1151$ & $309 / 1151$ & $309 / 1151$ & $309 / 1151$ \\
\hline \multicolumn{6}{|l|}{ Decrease in oil price } \\
\hline $\mathrm{ATT} \mathrm{OPT}^{-}$ & $0.00386 * * *$ & $0.00385^{* * *}$ & $0.00417^{* * *}$ & $0.00410 * * *$ & $0.00389^{* * *}$ \\
\hline T-stat. & $(4.24)$ & $(4.79)$ & $(6.01)$ & $(6.29)$ & $(5.82)$ \\
\hline Treated/Obs. & $340 / 1148$ & $340 / 1148$ & $340 / 1148$ & $340 / 1148$ & $340 / 1148$ \\
\hline
\end{tabular}

Notes: (1) Observed coefficient is treatment effect (the difference between the treated and controls). When oil pass-through is lower for the controls than the treated, observed coefficient shows a positive value, (2) t-statistics are presented in parenthesis. Standard errors are bootstrapped (using 500 iterations), (3) *,**,*** denotes significance at the 1,5 and $10 \%$. A high t-value indicates a significant gap between treated and controls, (4) Treated/Obs. is the number of treated observations over the sample size. 
Table 5: Average treatment effect of IT on oil price change pass-through to consumer inflation, when oil price increases

\begin{tabular}{|c|c|c|c|c|c|}
\hline PSM & $\begin{array}{c}\text { Nearest } \\
\text { neighbor }(1)\end{array}$ & $\begin{array}{c}\text { Nearest } \\
\text { neighbor }(5)\end{array}$ & Kernel & $\begin{array}{l}\text { Local- } \\
\text { linear }\end{array}$ & $\begin{array}{c}\text { Radius } \\
(.05)\end{array}$ \\
\hline \multicolumn{6}{|c|}{ All IT central banks (recall) } \\
\hline $\mathrm{ATT} \mathrm{OPT}^{+}$ & -0.000484 & -0.000652 & -0.000836 & $-0.00122^{*}$ & -0.00101 \\
\hline T-stat. & $(-0.47)$ & $(-0.82)$ & $(-1.02)$ & $(-1.66)$ & $(-1.45)$ \\
\hline Treated/Obs. & $309 / 1151$ & $309 / 1151$ & $309 / 1151$ & $309 / 1151$ & $309 / 1151$ \\
\hline \multicolumn{6}{|c|}{ Inflation up to $3 \%$} \\
\hline${\mathrm{ATT} \mathrm{OPT}^{+}}^{*}$ & $-0.00342^{* * *}$ & $-0.00346^{* * *}$ & $-0.00331^{* * *}$ & $-0.00380 * * *$ & $-0.00329 * * *$ \\
\hline T-stat. & $(-2.72)$ & $(-3.67)$ & $(-4.60)$ & $(-5.77)$ & $(-5.11)$ \\
\hline Treated/Obs. & $147 / 989$ & $147 / 989$ & $147 / 989$ & $147 / 989$ & $147 / 989$ \\
\hline \multicolumn{6}{|c|}{ Inflation up to $5 \%$} \\
\hline${\mathrm{ATT} \mathrm{OPT}^{+}}^{+}$ & $-0.00203^{* *}$ & $-0.00224^{* * *}$ & $-0.00213^{* * *}$ & $-0.00255^{* * *}$ & $-0.00223^{* * *}$ \\
\hline T-stat. & $(-2.08)$ & $(-2.71)$ & $(-3.30)$ & $(-4.06)$ & $(-3.75)$ \\
\hline Treated/Obs. & $227 / 1069$ & $227 / 1069$ & $227 / 1069$ & $227 / 1069$ & $227 / 1069$ \\
\hline \multicolumn{6}{|c|}{ Inflation up to $10 \%$} \\
\hline${\mathrm{ATT} \mathrm{OPT}^{+}}^{+}$ & -0.000789 & -0.000820 & -0.000945 & $-0.00134^{*}$ & -0.00108 \\
\hline T-stat. & $(-0.80)$ & $(-0.96)$ & $(-1.25)$ & $(-1.82)$ & $(-1.49)$ \\
\hline Treated/Obs. & $288 / 1130$ & $288 / 1130$ & $288 / 1130$ & $288 / 1130$ & $288 / 1130$ \\
\hline \multicolumn{6}{|c|}{ Most conservative central banks only } \\
\hline $\mathrm{ATT} \mathrm{OPT}^{+}$ & $-0.00236^{* *}$ & $-0.00200^{* *}$ & $-0.00236^{* * *}$ & $-0.00274^{* * *}$ & $-0.00208^{* * *}$ \\
\hline T-stat. & $(-2.13)$ & $(-2.07)$ & & $(-3.50)$ & $(-2.93)$ \\
\hline Treated/Obs. & $158 / 1016$ & $158 / 1016$ & $158 / 1016$ & $158 / 1016$ & $158 / 1016$ \\
\hline \multicolumn{6}{|c|}{ Least conservative central banks only } \\
\hline $\mathrm{ATT} \mathrm{OPT}^{+}$ & 0.000833 & -0.000144 & -0.0000897 & -0.000394 & -0.000846 \\
\hline T-stat. & $(0.61)$ & $(-0.12)$ & $(-0.08)$ & $(-0.37)$ & $(-0.87)$ \\
\hline Treated/Obs. & $136 / 994$ & $136 / 994$ & $136 / 9941$ & $136 / 994$ & $136 / 994$ \\
\hline
\end{tabular}

Notes: (1) Observed coefficient is treatment effect (the difference between the treated and controls). When oil pass-through is lower for the controls than the treated, observed coefficient shows a positive value, (2) t-statistics are presented in parenthesis. Standard errors are bootstrapped (using 500 iterations), (3) *,**,*** denotes significance at the 1,5 and $10 \%$. A high t-value indicates a significant gap between treated and controls, (4) Treated/Obs. is the number of treated observations over the sample size. (5) Most (least) conservative central bank are those ranked over (below) the median in the Central Bank Conservatism index (cons) by Levieuge et al. (2019). 
Table 6: Average treatment effect of IT on oil price change pass-through to consumer inflation, when oil price decreases

\begin{tabular}{|c|c|c|c|c|c|}
\hline PSM & $\begin{array}{c}\text { Nearest } \\
\text { neighbor(1) }\end{array}$ & $\begin{array}{c}\text { Nearest } \\
\text { neighbor }(5)\end{array}$ & Kernel & $\begin{array}{l}\text { Local- } \\
\text { linear }\end{array}$ & $\begin{array}{c}\text { Radius } \\
(.05)\end{array}$ \\
\hline \multicolumn{6}{|c|}{ All IT central banks (recall) } \\
\hline $\mathrm{ATT} \mathrm{OPT}^{-}$ & $0.00386^{* * *}$ & $0.00385^{* * *}$ & $0.00417^{* * *}$ & $0.00410^{* * *}$ & $0.00389^{* * *}$ \\
\hline T-stat. & $(4.24)$ & $(4.79)$ & $(6.01)$ & $(6.29)$ & $(5.82)$ \\
\hline Treated/Obs. & $340 / 1148$ & $340 / 1148$ & $340 / 1148$ & $340 / 1148$ & $340 / 1148$ \\
\hline \multicolumn{6}{|c|}{ Inflation below target } \\
\hline $\mathrm{ATT} \mathrm{OPT}^{-}$ & 0.00137 & 0.00150 & $0.00148^{* *}$ & $0.00154^{* *}$ & 0.000728 \\
\hline T-stat. & $(1.09)$ & $(1.62)$ & $(1.99)$ & $(2.00)$ & $(0.99)$ \\
\hline NbrTreated & $58 / 893$ & $58 / 893$ & $58 / 893$ & $58 / 893$ & $58 / 893$ \\
\hline \multicolumn{6}{|c|}{ Inflation close to target } \\
\hline $\mathrm{ATT} \mathrm{OPT}^{-}$ & $0.00349^{* * *}$ & $0.00290 * * *$ & $0.00315^{* * *}$ & $0.00313^{* * *}$ & $0.00285^{* * *}$ \\
\hline T-stat. & $(3.79)$ & $(3.83)$ & $(4.44)$ & $(4.60)$ & $(4.10)$ \\
\hline NbrTreated & $207 / 1042$ & $207 / 1042$ & $207 / 1042$ & $207 / 1042$ & $207 / 1042$ \\
\hline \multicolumn{6}{|c|}{ Inflation above target } \\
\hline $\mathrm{ATT} \mathrm{OPT}^{-}$ & $0.00603^{* * *}$ & $0.00763^{* * *}$ & $0.00801^{* * *}$ & $0.00780 * * *$ & $0.00735^{* * *}$ \\
\hline T-stat. & $(2.83)$ & $(3.91)$ & $(4.54)$ & $(4.63)$ & $(4.08)$ \\
\hline NbrTreated & $48 / 883$ & $48 / 883$ & $48 / 883$ & $48 / 883$ & $48 / 883$ \\
\hline \multicolumn{6}{|c|}{ Most conservative central banks only } \\
\hline $\mathrm{ATT} \mathrm{OPT}^{-}$ & $0.00273^{* * *}$ & $0.00245^{* * *}$ & $0.00298^{* * *}$ & $0.00309^{* * *}$ & $0.00281^{* * *}$ \\
\hline T-stat. & $(2.69)$ & $(2.68)$ & $(3.88)$ & $(4.27)$ & $(4.19)$ \\
\hline Treated/Obs. & $175 / 991$ & $175 / 991$ & $175 / 991$ & $175 / 991$ & $175 / 991$ \\
\hline \multicolumn{6}{|c|}{ Least conservative central banks only } \\
\hline $\mathrm{ATT} \mathrm{OPT}^{-}$ & $0.00421^{* * *}$ & $0.00455^{* * *}$ & $0.00469^{* * *}$ & $0.00450^{* * *}$ & $0.00441^{* * *}$ \\
\hline T-stat. & $(3.19)$ & $(4.10)$ & $(4.57)$ & $(4.59)$ & $(4.17)$ \\
\hline Treated/Obs. & $161 / 977$ & $161 / 977$ & $161 / 977$ & $161 / 977$ & $161 / 977$ \\
\hline \multicolumn{6}{|c|}{ IT for less than 3 years } \\
\hline optn ATT_3yfirst & $0.00426^{* * *}$ & $0.00462^{* * *}$ & $0.00444^{* * *}$ & $0.00436^{* * *}$ & $0.00409^{* * *}$ \\
\hline T-stat. & $(4.36)$ & $(5.31)$ & $(5.39)$ & $(5.17)$ & $(4.84)$ \\
\hline Treated/Obs. & $228 / 1022$ & $228 / 1022$ & $228 / 1022$ & $228 / 1022$ & $228 / 1022$ \\
\hline \multicolumn{6}{|c|}{ IT for more than 3 years } \\
\hline optn ATT_3yold & $0.00335^{* * *}$ & $0.00394^{* * *}$ & $0.00387 * * *$ & $0.00382^{* * *}$ & $0.00369^{* * *}$ \\
\hline T-stat. & $(3.88)$ & $(5.18)$ & $(5.61)$ & $(5.25)$ & $(5.52)$ \\
\hline Treated/Obs. & $314 / 1108$ & $314 / 1108$ & $314 / 1108$ & $314 / 1108$ & $314 / 1108$ \\
\hline
\end{tabular}

Notes: (1) Observed coefficient is treatment effect (the difference between the treated and controls). When oil pass-through is lower for the controls than the treated, observed coefficient shows a positive value, (2) t-statistics are presented in parenthesis. Standard errors are bootstrapped (using 500 iterations), (3) ***,*** denotes significance at the 1,5 and $10 \%$. A high t-value indicates a significant gap between treated and controls, (4) Treated/Obs. is the number of treated observations over the sample size. (5) Inflation is considered close to the target if with-in a $25 \%$ band around the target. (6) Most (least) conservative central bank are those ranked over (below) the median in the Central Bank Conservatism index (cons) by Levieuge et al. (2019). (7) IT age is computed using "soft" adoption dates. 
Table 7: Average treatment effect of IT on oil price change pass-through to consumer inflation, robustness

\begin{tabular}{|c|c|c|c|c|c|}
\hline PSM & $\begin{array}{c}\text { Nearest } \\
\text { neighbor }(1)\end{array}$ & $\begin{array}{c}\text { Nearest } \\
\text { neighbor }(5)\end{array}$ & Kernel & $\begin{array}{l}\text { Local- } \\
\text { linear }\end{array}$ & $\begin{array}{c}\text { Radius } \\
(.05)\end{array}$ \\
\hline \multicolumn{6}{|l|}{ Baseline (recall) } \\
\hline $\mathrm{ATT} \mathrm{OPT}^{+}$ & -0.000484 & -0.000652 & -0.000836 & $-0.00122^{*}$ & -0.00101 \\
\hline T-stat. & $(-0.47)$ & $(-0.82)$ & $(-1.02)$ & $(-1.66)$ & $(-1.45)$ \\
\hline Treated/Obs. & $309 / 1151$ & $309 / 1151$ & $309 / 1151$ & $309 / 1151$ & $309 / 1151$ \\
\hline $\mathrm{ATT} \mathrm{OPT}^{-}$ & $0.00386^{* * *}$ & $0.00385^{* * *}$ & $0.00417^{* * *}$ & $0.00410 * * *$ & $0.00389 * * *$ \\
\hline T-stat. & $(4.24)$ & $(4.79)$ & $(6.01)$ & $(6.29)$ & $(5.82)$ \\
\hline Treated/Obs. & $340 / 1148$ & $340 / 1148$ & $340 / 1148$ & $340 / 1148$ & $340 / 1148$ \\
\hline \multicolumn{6}{|c|}{ Excluding Great Recession area } \\
\hline $\mathrm{ATT} \mathrm{OPT}^{+} 1970-2007$ & -0.000886 & -0.00130 & -0.00123 & $-0.00149^{*}$ & $-0.00156^{*}$ \\
\hline T-stat & $(-0.57)$ & $(-1.21)$ & $(-1.45)$ & $(-1.81)$ & $(-1.81)$ \\
\hline Treated/Obs. & $150 / 992$ & $150 / 992$ & $150 / 992$ & $150 / 992$ & $150 / 992$ \\
\hline${\text { ATT } \text { OPT }^{-}}^{1970-2007}$ & $0.00338^{* * *}$ & $0.00357^{* * *}$ & $0.00405^{* * *}$ & $0.00393^{* * *}$ & $0.00361^{* * *}$ \\
\hline T-stat & $(3.02)$ & $(3.60)$ & $(4.71)$ & $(4.65)$ & $(4.60)$ \\
\hline Treated/Obs. & $179 / 987$ & $179 / 987$ & $179 / 987$ & $179 / 987$ & $179 / 987$ \\
\hline \multicolumn{6}{|c|}{ Excluding falling oil price area } \\
\hline $\mathrm{ATT} \mathrm{OPT}^{+} 1970-2013$ & -0.000488 & -0.000633 & -0.000606 & -0.00102 & -0.000760 \\
\hline T-stat & $(-0.46)$ & $(-0.70)$ & & $(-1.34)$ & $(-0.97)$ \\
\hline Treated/Obs. & $265 / 1107$ & $265 / 1107$ & $265 / 1107$ & $265 / 1107$ & $265 / 1107$ \\
\hline ATT OPT $^{-}$1970-2013 & $0.00375^{* * *}$ & $0.00378 * * *$ & $0.00419 * * *$ & $0.00412^{* * *}$ & $0.00389 * * *$ \\
\hline T-stat & $(4.02)$ & $(4.38)$ & $(6.04)$ & $(5.76)$ & $(5.76)$ \\
\hline Treated/Obs. & $297 / 1105$ & $297 / 1105$ & $297 / 1105$ & $297 / 1105$ & $297 / 1105$ \\
\hline \multicolumn{6}{|c|}{ Excluding oil exporters } \\
\hline $\mathrm{ATT} \mathrm{OPT}^{+}$ & -0.000732 & -0.00103 & -0.00109 & $-0.00137^{*}$ & -0.00137 \\
\hline & $(-0.67)$ & & & $(-1.65)$ & $(-1.63)$ \\
\hline Treated/Obs. & $240 / 1082$ & $240 / 1082$ & $240 / 1082$ & $240 / 1082$ & $240 / 1082$ \\
\hline $\mathrm{ATT} \mathrm{OPT}^{-}$ & $0.00381^{* * *}$ & $0.00381^{* * *}$ & $0.00411^{* * *}$ & $0.00396 * * *$ & $0.00383^{* * *}$ \\
\hline T-stat & $(3.98)$ & $(4.36)$ & $(5.34)$ & $(5.00)$ & $(5.23)$ \\
\hline Treated/Obs. & $277 / 1085$ & $277 / 1085$ & $277 / 1085$ & $277 / 1085$ & $277 / 1085$ \\
\hline \multicolumn{6}{|c|}{ Excluding if a large proportion of consumer prices are administered } \\
\hline $\mathrm{ATT} \mathrm{OPT}^{+}$ & -0.00105 & -0.001000 & -0.00121 & $-0.00163^{* *}$ & $-0.00160^{* *}$ \\
\hline T-stat & $(-0.86)$ & $(-1.00)$ & $(-1.57)$ & $(-2.15)$ & $(-2.21)$ \\
\hline Treated/Obs. & $196 / 1038$ & $196 / 1038$ & $196 / 1038$ & $196 / 1038$ & $196 / 1038$ \\
\hline $\mathrm{ATT} \mathrm{OPT}^{-}$ & $0.00353^{* * *}$ & $0.00397^{* * *}$ & $0.00422^{* * *}$ & $0.00404^{* * *}$ & $0.00398^{* * *}$ \\
\hline T-stat & $(3.04)$ & (4.11) & $(4.81)$ & $(4.95)$ & $(4.94)$ \\
\hline Treated/Obs. & $225 / 1033$ & $225 / 1033$ & $225 / 1033$ & $225 / 1033$ & $225 / 1033$ \\
\hline
\end{tabular}

Notes: (1) Observed coefficient is treatment effect (the difference between the treated and controls). When oil pass-through is lower for the controls than the treated, observed coefficient shows a positive value, (2) t-statistics are presented in parenthesis. Standard errors are bootstrapped (using 500 iterations), (3) ***,*** denotes significance at the 1,5 and $10 \%$. A high t-value indicates a significant gap between treated and controls, (4) Treated/Obs. is the number of treated observations over the sample size. (5) A country has a large proportion of administered prices if its Price Policy score (CEPII IPD database, reference B4040) is greater than the median. 


\section{References}

BACON, R. W. (1991): "Rockets and feathers: the asymmetric speed of adjustment of UK retail gasoline prices to cost changes," Energy Economics, 13(3), 211-218.

Balima, W. H., J.-L. Combes, and A. Minea (2017): "Sovereign debt risk in emerging market economies: Does inflation targeting adoption make any difference?," Journal of International Money and Finance, 70, 360 - 377.

Baumeister, C., And L. Kilian (2011): "Real-Time Forecasts of the Real Price of Oil," Journal of Business \& Economic Statistics, 30(2), 326-336.

Bernanke, B. S., and F. S. Mishkin (1997): "Inflation Targeting: A New Framework for Monetary Policy?," Journal of Economic Perspectives, 11(2), 97-116.

Bhanumurthy, N. R., S. Das, and S. Bose (2012): "Oil Price Shock, Passthrough Policy and its Impact on India," Working Papers 12/99, National Institute of Public Finance and Policy.

Bodea, C., And R. Hicks (2015): "International Finance and Central Bank Independence: Institutional Diffusion and the Flow and Cost of Capital," The Journal of Politics, 77(1), 268-284.

Choi, S., D. Furceri, P. Loungani, S. Mishra, and M. Poplawski-Ribeiro (2018): "Oil prices and inflation dynamics: Evidence from advanced and developing economies," Journal of International Money and Finance, 82(C), 71-96.

Crowe, C., And E. E. Meade (2007): "The Evolution of Central Bank Governance around the World," Journal of Economic Perspectives, 21(4), 69-90.

Garriga, A. (2016a): "Central Bank Independence in the World: A New Data Set," Harvard Dataverse.

Garriga, A. C. (2016b): "Central Bank Independence in the World: A New Data Set," International Interactions, 42(5), 849-868.

Gopinath, G., O. Itskhoki, and R. Rigobon (2010): "Currency Choice and Exchange Rate Pass-Through," American Economic Review, 100(1), 304-336.

Hammond, G. (2012): State of the art of inflation targeting. Centre for Central Banking Studies, Bank of England, 4 edn.

Hooker, M. A. (2002): "Are Oil Shocks Inflationary? Asymmetric and Nonlinear Specifications versus Changes in Regime," Journal of Money, Credit and Banking, $34(2), 540-561$. 
Ilzetzki, E., C. M. Reinhart, and K. S. Rogoff (2017): "Exchange Arrangements Entering the 21st Century: Which Anchor Will Hold?," NBER Working Papers 23134, National Bureau of Economic Research, Inc.

Kilian, L., And L. T. Lewis (2011): "Does the Fed Respond to Oil Price Shocks?," Economic Journal, 121(555), 1047-1072.

Kilian, L., and C. Park (2009): "The Impact Of Oil Price Shocks On The U.S. Stock Market," International Economic Review, 50(4), 1267-1287.

Levieuge, G., Y. Lucotte, and F. Pradines-Jobet (2019): "Central banks preferences and banking sector vulnerability," Journal of Financial Stability.

Lopez-Villanicencio, A., And M. Pourroy (2017): "IT Countries: A Breed Apart? the case of Exchange Rate Pass-Through," Discussion paper.

Minea, A., and R. Tapsoba (2014): "Does inflation targeting improve fiscal discipline?," Journal of International Money and Finance, 40(C), 185-203.

Mishrin, F. S. (2004): "Can Inflation Targeting Work in Emerging Market Countries?," NBER Working Papers 10646, National Bureau of Economic Research, Inc.

(2007): "Will Monetary Policy Become More of a Science?," Working Paper 13566, National Bureau of Economic Research.

Mishinin, F. S., and K. Schmidt-Hebbel (2001): "One Decade of Inflation Targeting in the World: What Do We Know and What Do We Need to Know?," NBER Working Papers 8397, National Bureau of Economic Research, Inc.

Otker, I., D. VÁvra, F. F. Vazquez, L. I. Jácome, K. F. Habermeier, K. Ishi, A. Giustiniani, and T. Kisinbay (2009): "Inflation Pressures and Monetary Policy Options in Emerging and Developing Countries. A Cross Regional Perspective," IMF Working Papers 09/1, International Monetary Fund.

Roger, S. (2009): "Inflation Targeting at 20 - Achievements and Challenges," IMF Working Papers 09/236, International Monetary Fund.

Roger, S., And M. R. Stone (2005): "On Target? the International Experience with Achieving Inflation Targets," IMF Working Papers 05/163, International Monetary Fund.

Rose, A. K. (2007): "A stable international monetary system emerges: Inflation targeting is Bretton Woods, reversed," Journal of International Money and Finance, 26(5), 663-681. 
Svensson, L. E. O. (1997): "Inflation forecast targeting: Implementing and monitoring inflation targets," European Economic Review, 41(6), 1111-1146.

Vega, M., And D. Winkelried (2005): "Inflation Targeting and Inflation Behavior: A Successful Story?," International Journal of Central Banking, 1(3). 
Table 8: IT data-set composition

\begin{tabular}{lcc}
\hline Country & IT Soft & IT Full-Fledge \\
\hline New Zealand & 1990 & 1990 \\
Canada & 1991 & 1992 \\
Chile & 1991 & 2000 \\
Israel & 1992 & 1997 \\
Australia & 1993 & 1995 \\
Finland* & 1993 & 1994 \\
Sweden & 1993 & 1995 \\
United Kingdom & 1993 & 1993 \\
Spain* & 1995 & 1995 \\
Czech Republic & 1998 & 1998 \\
Korea Republic & 1998 & 1998 \\
Brazil & 1999 & 1999 \\
Mexico & 1999 & 2001 \\
Poland & 1999 & 1999 \\
Colombia & 2000 & 2000 \\
South Africa & 2000 & 2000 \\
Switzerland & 2000 & 2000 \\
Thailand & 2000 & 2000 \\
Hungary & 2001 & 2002 \\
Iceland & 2001 & 2001 \\
Norway & 2001 & 2001 \\
Philippines & 2002 & 2002 \\
Slovak Republic* & 2005 & 2005 \\
Indonesia & 2005 & 2006 \\
Romania & 2005 & 2006 \\
Turkey & 2006 & 2006 \\
\hline Notes: The starting date is the current year of \\
adoption if it took place from January to June, \\
the following year if it took place form July to De- \\
cember. The ending date is 2016 for all countries \\
but Finland, Slovak Republic and Spain which \\
adopted the Euro in 1999,2009 and 1999 respec- \\
tively. & & \\
& &
\end{tabular}

\section{A Variables and definition:}

Central Bank Independence Dummy variable taking the value 1 if the country is IT and has indepedence greater than median, according to Bodea and Hicks (2015), Crowe and Meade (2007) and Garriga (2016b) indices . Source: Author's calcula- 
tions based on Garriga (2016a)

Central Bank Conservatism Index taking values from 0 to 1 , greater values are associated to more conservative preferences, defined as a preference for price stability over output. Source: Levieuge, Lucotte, and Pradines-Jobet (2019)

Exchange Rate Variation $(\Delta e)$ : Quarterly year-to-year difference of the log nominal effective exchange rate. Domestic currency per unit of foreign currency: an increase implies a nominal depreciation.

Source: BIS-Bank of International Settlements

Fossil: Lag fossil fuel energy consumption (\% of total) .

Source: World Bank (EG.USE.COMM.FO.ZS)

GDP Growth $(\Delta y)$ : Quarterly seasonally adjusted year-to-year difference of the $\log$ GDP in real terms.

Source: IMF- International Financial Statistics

GDP Share: The share of world GDP (domestic current US\$ GDP over world current US\$ GDP, \%, )

Source: Author's calculations \& World Bank (ny.gdp.mktp.cd)

Import: Lag fuel imports (\% of merchandise imports)

Source: World Bank (TM.VAL.FUEL.ZS.UN)

Inflation $(\Delta p)$ : Quarterly seasonally adjusted year-to-year difference of the log consumer price index.

Source: IMF- International Financial Statistics

Inflation Targeting: Ful Fledged : Dummy variable that takes on the value one if in a given year the country operates under IT, and zero otherwise. The default IT variable corresponds to the full-fledge definition: countries that make an explicit commitment to meet a specified inflation rate or range within a specified time frame, regularly announce their targets to the public, and have institutional arrangements to ensure that the central bank is accountable for meeting the target. Source: Rose (2007), Roger (2009) and Minea and Tapsoba (2014)

Inflation Targeting: Soft Dummy variable that takes on the value one starting in the period in which the country officially announced the adoption of IT (and 
for all subsequent years), and zero otherwise. Under soft IT, the inflation target may coexists with other nominal anchors.

Source: Rose (2007), Roger (2009) and Minea and Tapsoba (2014)

Inflation Volatility: Lag standard deviation of the annualized monthly inflation rates of years $t$ and $t-1$

Source: Author's calculations based on the consumer price index provided by the IMF- International Financial Statistics

Money: Lag money-to-GDP ratio (Broad money \% of GDP) .

Source: World Bank (FM.LBL.BMNY.GD.ZS) and IMF IFS (35L..ZK)

Polity2: Polity2 index taking values from -10 (very autocratic) to +10 (very democratic) and constructed by subtracting the democracy score from the autocracy score Source: Polity IV Project (Polity2)

Price Policy: The "Freedom of prices" index takes value from 1 to 5 based on a measure of direct commodity price and gasoline subsidies.

Source: CEPII IPD database, reference $B 4040$

Regime: Years since the adoption of a flexible exchange rate regime Source: Ilzetzki, Reinhart, and Rogoff (2017), authors' calculation

Supply Shocks $\left(\Delta p^{*}\right)$ : Quarterly seasonally adjusted year-to-year difference of the average OECD producer price index.

Source: IMF- International Financial Statistics 
Table 9: Symmetric and asymmetric oil pass-through coefficients.

\begin{tabular}{|c|c|c|c|c|c|c|c|}
\hline \multirow{3}{*}{$\begin{array}{l}\text { OPT: } \\
\text { Country: }\end{array}$} & \multirow{2}{*}{\multicolumn{2}{|c|}{$\frac{\text { Symmetric PT }}{\beta}$}} & \multicolumn{5}{|c|}{ Asymmetric PT } \\
\hline & & & \multicolumn{2}{|c|}{$\beta^{+}$} & \multicolumn{2}{|c|}{$\beta^{-}$} & \multirow{2}{*}{$\begin{array}{c}\beta^{+}=\beta^{-} \\
\text {Prob. }\end{array}$} \\
\hline & Coeff. & (t-stat) & Coeff. & (t-stat) & Coeff. & (t-stat) & \\
\hline Argentina & -0.014 & -1.61 & -0.006 & -0.46 & -0.023 & -1.78 & 0.195 \\
\hline Australia* & 0.005 & 2.01 & 0.010 & 2.56 & -0.001 & -0.24 & 0.107 \\
\hline Austria & 0.007 & 5.88 & 0.010 & 5.39 & 0.003 & 1.57 & 0.055 \\
\hline Belgium & 0.009 & 5.81 & 0.013 & 5.43 & 0.004 & 1.54 & 0.033 \\
\hline Brazil* & 0.006 & 1.32 & 0.011 & 1.91 & -0.001 & -0.22 & 0.177 \\
\hline Canada* & 0.011 & 6.27 & 0.011 & 4.68 & 0.011 & 3.49 & 0.964 \\
\hline Chile* & 0.007 & 2.52 & 0.011 & 2.35 & 0.003 & 0.51 & 0.304 \\
\hline China & 0.001 & 0.27 & -0.002 & -0.35 & 0.005 & 0.75 & 0.468 \\
\hline Colombia* & 0.004 & 1.50 & 0.008 & 1.91 & 0.000 & 0.07 & 0.234 \\
\hline Czech Rep.* & 0.011 & 2.89 & 0.012 & 1.97 & 0.009 & 1.62 & 0.780 \\
\hline Denmark & 0.007 & 2.92 & 0.016 & 4.71 & -0.006 & -1.50 & 0.000 \\
\hline Estonia & 0.009 & 2.19 & 0.002 & 0.28 & 0.017 & 2.22 & 0.226 \\
\hline Finland* & 0.008 & 4.18 & 0.011 & 4.12 & 0.002 & 0.76 & 0.039 \\
\hline France & 0.008 & 5.64 & 0.012 & 6.06 & 0.002 & 0.90 & 0.003 \\
\hline Germany & 0.004 & 3.98 & 0.003 & 1.82 & 0.007 & 3.04 & 0.023 \\
\hline Greece & 0.007 & 1.76 & -0.000 & -0.09 & 0.018 & 2.27 & 0.049 \\
\hline Hong Kong & 0.002 & 0.57 & -0.002 & -0.47 & 0.007 & 1.21 & 0.287 \\
\hline Hungary* & 0.004 & 1.36 & 0.003 & 0.49 & 0.007 & 1.15 & 0.667 \\
\hline Iceland* & 0.035 & 4.41 & 0.041 & 3.33 & 0.027 & 1.72 & 0.052 \\
\hline India & 0.009 & 2.19 & 0.015 & 1.92 & 0.004 & 0.51 & 0.394 \\
\hline Indonesia* & 0.023 & 1.85 & 0.027 & 1.21 & 0.020 & 0.91 & 0.835 \\
\hline Ireland & 0.014 & 4.65 & 0.021 & 4.54 & 0.004 & 0.69 & 0.036 \\
\hline Israel* & 0.001 & 0.33 & 0.001 & 0.12 & 0.002 & 0.28 & 0.925 \\
\hline Italy & 0.009 & 4.91 & 0.017 & 5.00 & 0.002 & 0.45 & 0.012 \\
\hline Japan & 0.008 & 3.21 & 0.015 & 3.74 & -0.001 & -0.17 & 0.030 \\
\hline Korea* & 0.029 & 5.77 & 0.041 & 5.57 & 0.011 & 1.13 & 0.023 \\
\hline Latvia & 0.005 & 1.48 & 0.006 & 0.84 & 0.005 & 0.80 & 0.963 \\
\hline Lithuania & 0.005 & 1.34 & 0.007 & 0.99 & 0.003 & 0.41 & 0.203 \\
\hline Malaysia & 0.007 & 2.29 & 0.005 & 0.96 & 0.010 & 1.96 & 0.479 \\
\hline Mexico* & 0.024 & 2.14 & 0.024 & 1.47 & 0.030 & 1.41 & 0.828 \\
\hline Netherlands & 0.008 & 4.16 & 0.007 & 2.09 & 0.009 & 2.47 & 0.744 \\
\hline New Zealand* & 0.009 & 3.48 & 0.012 & 2.97 & 0.004 & 1.20 & 0.093 \\
\hline Norway* & 0.006 & 2.34 & 0.013 & 3.81 & -0.006 & -1.31 & 0.002 \\
\hline Philippines* & 0.009 & 2.06 & 0.005 & 0.56 & 0.015 & 1.89 & 0.442 \\
\hline Poland* & 0.009 & 3.04 & 0.017 & 3.44 & 0.001 & 0.22 & 0.042 \\
\hline Portugal & 0.007 & 1.43 & 0.009 & 1.24 & 0.004 & 0.34 & 0.684 \\
\hline Romania* & -0.010 & -0.32 & -0.049 & -0.92 & 0.032 & 0.57 & 0.363 \\
\hline Russia & 0.007 & 0.90 & 0.040 & 3.76 & -0.043 & -3.03 & 0.000 \\
\hline Singapore & 0.007 & 2.72 & 0.011 & 2.93 & 0.001 & 0.23 & 0.028 \\
\hline Slovak Rep.* & 0.016 & 2.86 & 0.024 & 2.48 & 0.007 & 0.72 & 0.030 \\
\hline Slovenia & 0.008 & 2.99 & 0.011 & 2.30 & 0.005 & 1.12 & 0.045 \\
\hline South Africa* & 0.009 & 3.04 & 0.014 & 3.01 & 0.004 & 0.69 & 0.020 \\
\hline Spain* & 0.007 & 2.61 & 0.011 & 2.78 & 0.001 & 0.08 & 0.006 \\
\hline Sweden* & 0.013 & 5.13 & 0.016 & 4.11 & 0.010 & 2.13 & 0.461 \\
\hline Switzerland* & 0.004 & 2.61 & 0.001 & 0.51 & 0.008 & 2.71 & 0.017 \\
\hline Thailand* & 0.009 & 2.32 & 0.003 & 0.51 & 0.016 & 2.43 & 0.017 \\
\hline Turkey* & 0.042 & 3.65 & 0.039 & 3.10 & 0.025 & 1.33 & 0.013 \\
\hline United Kingdom* & 0.009 & 3.65 & 0.013 & 3.44 & 0.003 & 0.70 & 0.007 \\
\hline United States & 0.013 & 6.87 & 0.018 & 6.75 & 0.007 & 2.18 & 0.008 \\
\hline
\end{tabular}

Notes: (a) This table shows the coefficients the OLS estimation of Eq. (1) and (2); (b) ITers are denoted with a star $\left(^{*}\right),(\mathrm{c}) \beta^{+}=\beta^{-}$is the $\chi$-test probability for the Wald test. 
Table 10: Average treatment effect of IT on oil price change pass-through. Robustness test using alternative measures of oil and lagged variables in the benchmark equation.

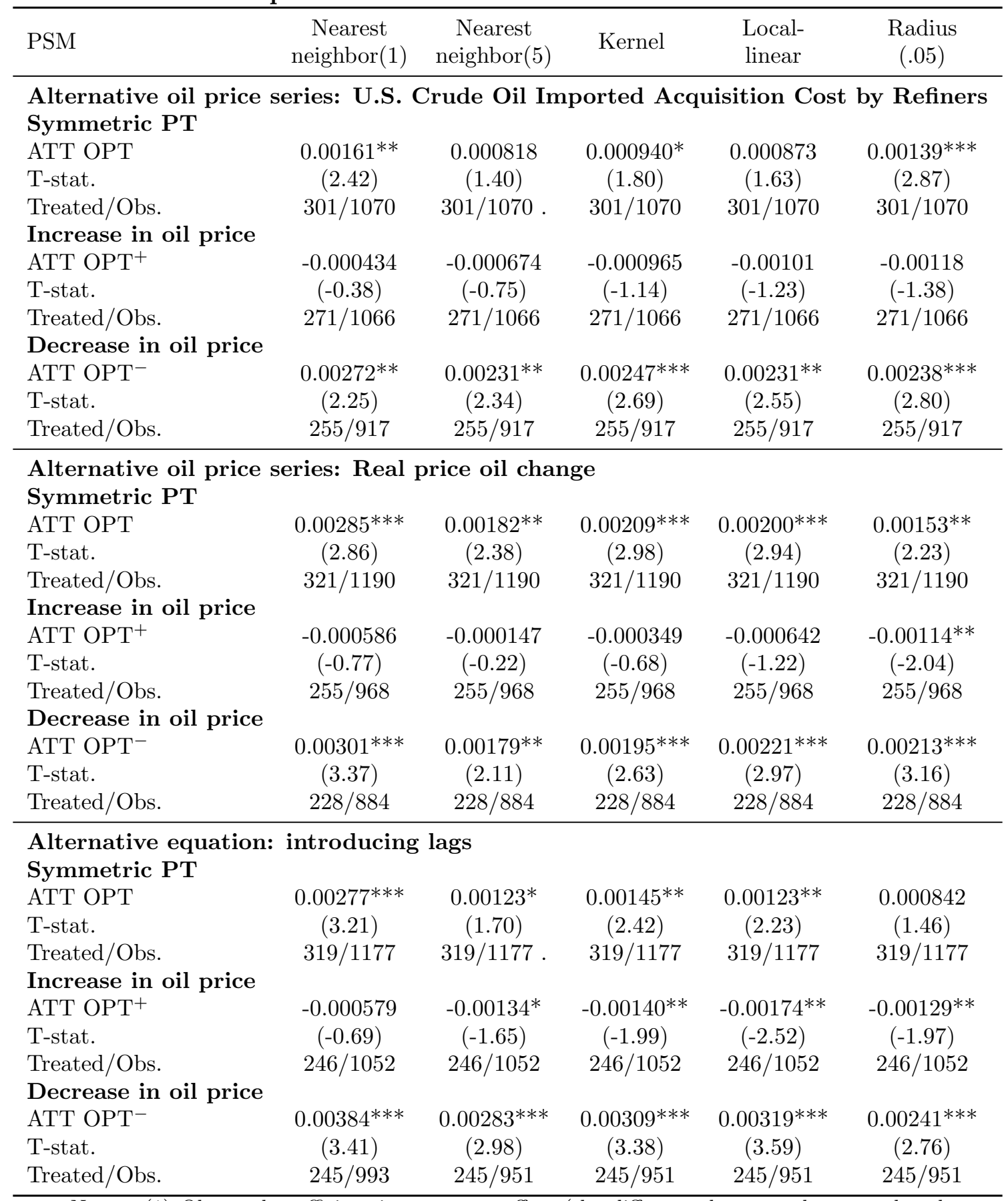

Notes: (1) Observed coefficient is treatment effect (the difference between the treated and controls). When oil pass-through is lower for the controls than the treated, observed coefficient shows a positive value, (2) t-statistics are presented in parenthesis. Standard errors are bootstrapped (using 500 iterations), (3)*,**,*** denotes significance at the 1,5 and $10 \%$. A high t-value indicates a significant gap between treated and controls, (4) Treated/Obs. is the number of treated observations over the sampid size. 
Figure 1: Oil Pass-Through to Inflation
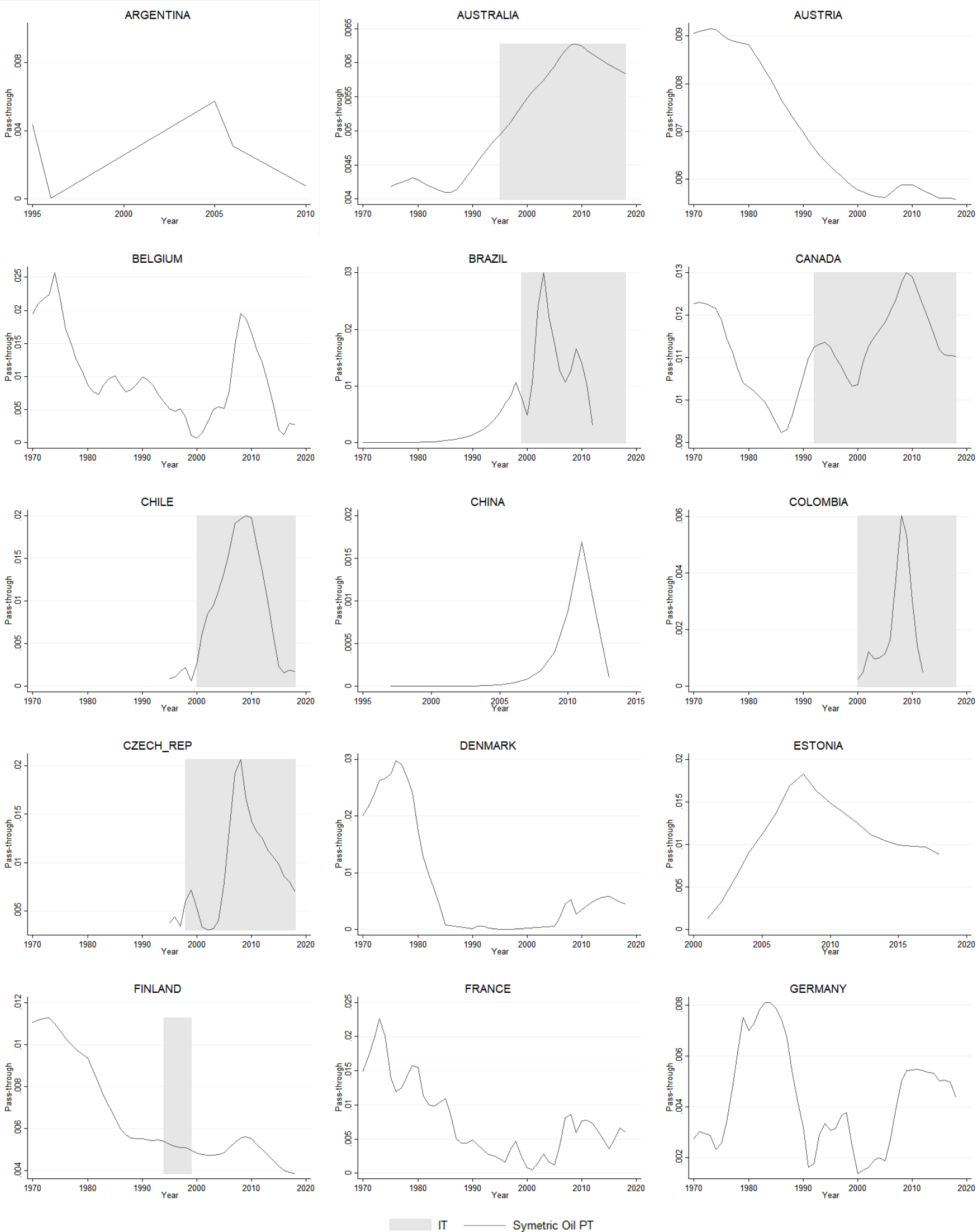
Figure 2: Oil Pass-Through to Inflation (cont.)
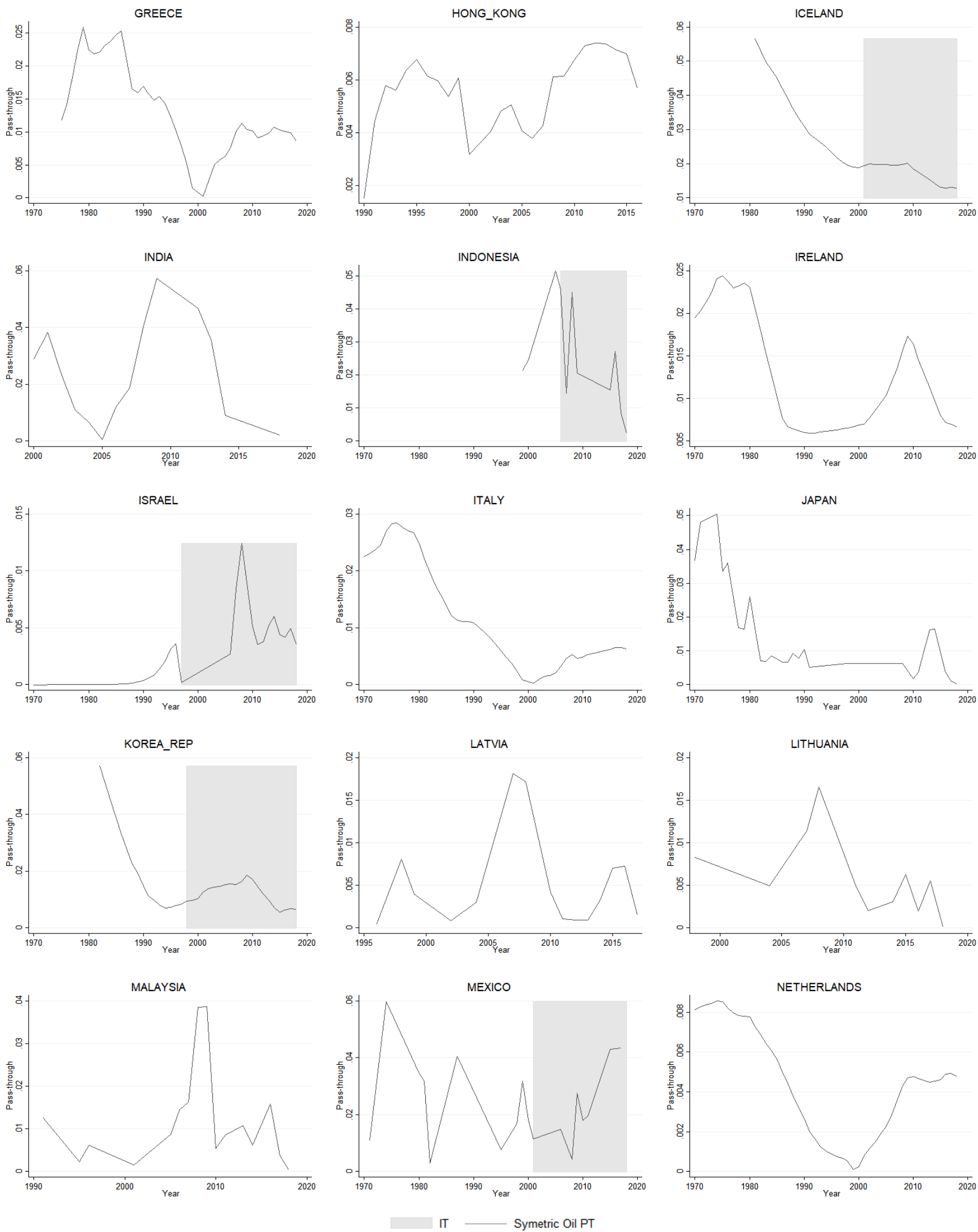
Figure 3: Oil Pass-Through to Inflation (cont.)
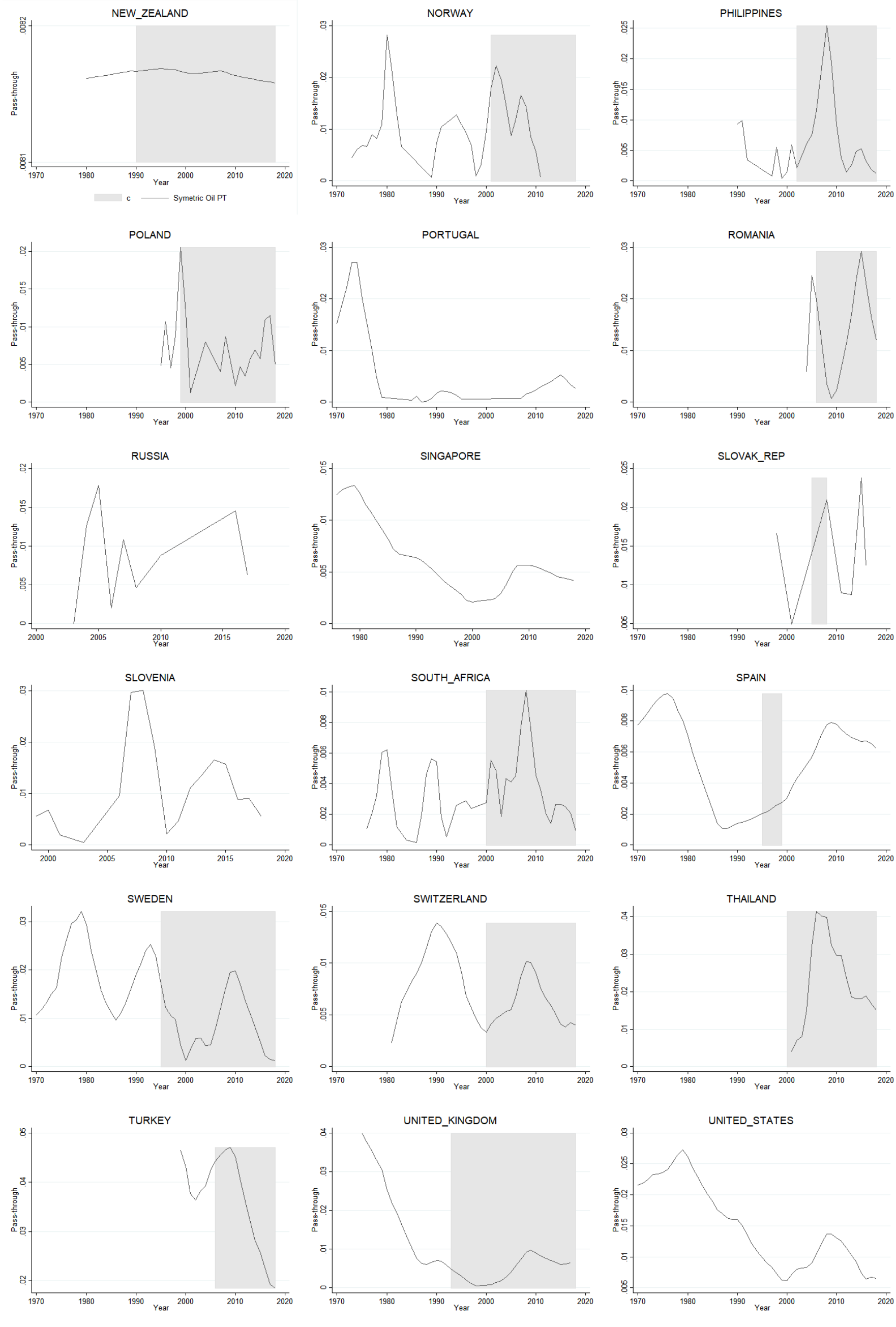